\title{
Una aproximación a la gerencia del siglo XXI
}

\author{
An approach to management of the century \\ Une approximation à la gestion du XXI siècle
}

\section{Resumen}

Diferentes autores en el mundo occidental, desde sus diferentes disciplinas, han hecho explícita su preocupación por la crisis que atraviesa actualmente la administración denominada de tipo tradicional, implicando que los fundamentos dominantes de la dirección administrativa soportados hoy, por un paradigma funcionalista, merezcan una reflexión que debe invitar a un cambio del mismo, pues sus consecuencias actuales atentan contra el equilibrio de la comunidad y de la naturaleza del mundo. Desde el punto de vista del espíritu capitalista, la acumulación de capital en las grandes compañías actuales, puede explicarse a partir de las conductas asumidas por los dueños del capital en las organizaciones que ejercen las funciones de la alta gerencia, donde sus comportamientos en la empresa, conducentes a maximizar cada vez más su capital, afectan de manera negativa a los seres humanos que trabajan en sus organizaciones, la sociedad donde sus empresas tienen su campo de acción y la naturaleza misma. Hablar de una crisis de la administración tradicional y sus consecuencias, no obliga sólo a reconocer tal afirmación, sino además, a ofrecer alternativas que posibiliten cambios que provoquen armonía entre los diferentes actores involucrados en el ejercicio administrativo; en este sentido, el objetivo del artículo, además de corresponder metodológicamente a una revisión teórica de los planteamientos realizados por diferentes autores reconocidos en este campo, propone, a partir de los hallazgos realizados y las reflexiones propuestas, introducir un tema de discusión que posibilite el análisis propuesto y brindar algunas opciones como inicio de debate y deliberación sobre la gerencia actual de las organizaciones, las cuales es deber seguir profundizando

Palabras clave: crematística, administración tradicional, crisis, alienación, radical-humanismo.

Artículo Tipo: de reflexión Según Clasificación Colciencias

Fecha de recepción: 10 de Febrero de 2011 Fecha de corrección: 22 de junio de 2011 Fecha de aprobación: 22 de junio de 2011

* Este documento surge a partir de las reflexiones que sobre el tema ya se han venido dando en diferentes escenarios académicos del mundo y el país, para dar unos ejemplos de lo que ha pasado sólo en Colombia se cuentan; el seminario internacional “Administración y Nueva Economía: Los Retos de la Globalización siglo XXI” realizado en el año 2001, el VI Congreso Nacional de Administración “Administración: Una Nueva Perspectiva para América Latina” realizado en el año 2004 y el primer seminario sobre "Nuevo Pensamiento Administrativo" realizado en la ciudad de Cali en el año 2004. Eventos asociados los diferentes trabajos y análisis motivados por la cátedra del doctorado en Administración de la Universidad de EAFIT denominada Nuevas Tendencias en Administración. 


\section{An approach to management of the century}

\author{
Una aproximación a la gerencia \\ del siglo XXI
}

\author{
Une approximation à la gestion du XXI \\ siècle
}

\section{Abstract}

Different authors in the western world from their different disciplines, have made their worry explicit for the crisis that crosses nowadays the administration called of traditional type, implying that the dominant foundations of the administrative direction supported today, by a functionalist paradigm, deserve a reflection that must invite to a change of the same type, since its current consequences break the equilibrium of the community and of the nature of the world. From the point of view of the capitalist spirit, the capital accumulation in the big existing companies, it is explained from the conducts assumed by the owners of the capital in the organizations, they exercise the functions of the top management, where their behaviors in the company, conducive to maximizing increasingly their capital, they affect in a negative way the human beings who are employed at their organizations, the humanity where their companies have their field of action and the nature itself.In this respect, it is necessary to approach a series of elements that give foundation to the need to explore new ways on the part of the administrative exercise with the intention of identifying the reasons of the current results, which, from a capitalist focus and utilitarian of the traditional administration, have produced a deviation that does not benefit for anything the environments in which the organizations are immersed.To speak about a crisis of the traditional administration and its consequences, it does not force to recognize only such an affirmation, but in addition, to offering alternatives that make possible changes that provoke harmony between the different actors involved in the administrative exercise, in this sense the aim of the article, as well as methodologically correspond to a theoretical review of the proposals made by different authors recognized in this field, proposed from the findings and reflections proposals to bring in an issue that will enable the proposed analysis and provide some options as the start of debate and discussion on the current management of the organizations, which is the duty, continue to deepen.

Keywords: chrematistics, traditional administration, crisis, alienation, radical humanism.
Une approximation à la gestion du XXI siècle

\author{
Una aproximación a la gerencia \\ del siglo XXI
}

\author{
An approach to management of the \\ century
}

\section{Résumée}

Différents auteurs du monde occidental, à partir de leurs différentes disciplines, ont fait explicite leur préoccupation pour la crise actuelle de la gestion dénommée de type traditionnel, ce qui implique que les fondements dominants de la direction administrative, supportés aujourd'hui par un paradigme fonctionnaliste, méritent une réflexion qui doit promouvoir un changement de celui-ci, parce que ses conséquences actuelles attentent contre l'équilibre de la communauté et de la nature du monde. Du point de vue de l'esprit capitaliste, l'accumulation du capital dans les grandes compagnies actuelles, peut s'expliquer à partir des conduites des propriétaires du capital dans les organisations, qui exercent des fonctions de haute gestion. Leurs comportements dans l'entreprise, ayant toujours pour but la maximisation du capital, affectent négativement les êtres humains qui travaillent dans leurs organisations, la société où leurs entreprises ont leur champ d'action, et la nature même. Parler d'une crise de l'administration traditionnelle et de ses conséquences, n'oblige pas seulement à reconnaitre telle affirmation, mais aussi, à offrir des alternatives qui rendent possible des changements qui produisent une harmonie entre les différents acteurs involucrés dans l'exercice administratif ; en ce sens, l'objet de cet article, en plus de correspondre méthodologiquement à une révision théorique des exposés réalisés par les différents auteurs reconnus sur ce domaine, propose, à partir des découvertes réalisées et des réflexions suggérées, la présentation d'un sujet de discussion qui rend possible l'analyse proposée et offrir quelques options qui servent pour introduire le débat et la délibération sur la gestion actuelle des organisations. Continuer avec l'approfondissement de ces options, constitue un devoir .

Mots clef: chrématistique, administration traditionnelle, crises, aliénation, radical-humanisme. 


\section{Una aproximación a la gerencia del siglo XXI}

\section{Introducción}

La gestión administrativa de tipo occidental se encuentra afectada por diferentes conceptos y posiciones asumidos en variados contextos que tocan el ejercicio administrativo, tales como el espíritu capitalista, la libertad, el utilitarismo y la posición ofrecida por la administración científica.

Desde el punto de vista del espíritu capitalista trabajado por Max Weber, teniendo en cuenta diferentes conceptos, entre los que se encuentra el calvinismo individualista, por ejemplo, se parece alimentar el concepto que del capital ha interiorizado la alta gerencia en las organizaciones de hoy.

La formación de estos capitales en las grandes compañías actuales se pueden relacionar con un proceder de tipo burgués ${ }^{1}$ en la actualidad, donde las conductas asumidas por los dueños del capital en las organizaciones que ejercen las funciones de la alta gerencia, podrían encontrar aquí, explicación a muchos de sus comportamientos en la empresa, conducentes a maximizar cada vez más su capital en contra de los seres humanos que trabajan en sus organizaciones, y de la sociedad donde sus empresas tienen su campo de acción y de la naturaleza misma.

Teóricamente hablar de máxima productividad como la causa de la máxima prosperidad (Taylor,1997,p.19), incluso aludiendo a algunos casos que desde la práctica así lo demuestran, seguramente no correspondería a este tiempo, pues la realidad organizacional de hoy, dedica gran parte del esfuerzo gerencial a lograr el máximo de productividad sólo con al ánimo de maximizar el capital, sin importar si logra que el entorno, tanto interno como externo, en el cual se desarrolla, perciba esa misma dedicación por parte de la gerencia, con el objetivo de alcanzar una máxima prosperidad que beneficie a todos. Es pertinente aclarar y no confundir la prosperidad de la que se habla aquí, con la que puede pregonar la alta dirección de la organización, en el ofrecimiento a los demandantes de los productos o servicios que ella ofrece y que al adquirirlos les permite lograrla.
Dos categorías sirven de marco introductorio ha lo que se a venido planteando, y tienen que ver con una de carácter biológico y otra de carácter social.

En este sentido, desde la categoría biológica, la propuesta darwiniana relacionada con la tendencia general hacia el progreso, que contempla una competencia entre organismos vivos (para el caso de la intencionalidad que aquí se busca, se contemplará únicamente la categoría de los seres humanos dentro de los organismos vivos) con el fin de garantizar la supervivencia, a través de la conquista de recursos que son limitados (Gould,1997, p.153), aunado al hecho, que son estos seres humanos los que tienen la posibilidad de generar cambios de orden cultural que pueden, bajo esta concepción, originar algún tipo de progreso (Gould, 1997, p.233).

Se puede aplicar a las compañías de hoy, que consideradas desde el punto de vista sistémico, como un sistema abierto que interactúa con el entorno donde existen otras organizaciones dedicadas a ofrecer los mismos productos y/o servicios, conformadas por hombres que laboran en ellas, sólo buscan en la dinámica organizacional actual, competir para lograr la mayor cantidad de recursos que les permitan sobrevivir; recursos que para este caso y como lo menciona Paul Hopkins, se ven reflejados en la necesidad de una rentabilidad monetaria que deja claro los riesgos que esta propuesta implica, relacionados con una confusión de intereses entre las organizaciones y la sociedad que genera divergencias.

Esta confusión de intereses para la gestión gerencial de los hombres en las organizaciones pierde importancia dada la idea de supervivencia absoluta que rige el entorno empresarial en la lucha del logro económico y que tradicionalmente ha desconocido los intereses reales de la comunidad y de algunos integrantes de la organización.

Así, la administración de tipo occidental, parece encontrar razón en lo biológico para justificar de alguna manera el comportamiento del hombre en las organizaciones de hoy.

1. No se pretende utilizar el término burguesía de manera textual como significado absoluto para identificar a las personas que ocupan cargos de alta gerencia en las organizaciones, pero si como un referente que da luz de superioridad de dichas personas. 
Abordando la categoría de lo social, es pertinente mencionar los comportamientos asumidos por los empresarios en la primera fase de la industrialización, descritos para el caso de Inglaterra, por Reinhard Bendix en su obra "Trabajo y Autoridad en la Gran Industria".

Allí los estados de arrogancia asumidos por los artesanos que habían llegado a constituirse en empresarios sobre las clases sociales inferiores, eran explicados por el sacrificio llevado a cabo por dichos artesanos para llegar a tal reconocimiento.

No cabe duda que las diferentes situaciones en contexto, de alguna manera alimentaron dichos comportamientos: la oferta de mano de obra infantil y las ayudas de la parroquia en contraposición a la baja en los salarios de los trabajadores, posiblemente nutrieron estos estados de arrogancia que con el tiempo originaron procesos reformistas en la búsqueda de la reivindicación de los derechos civiles de las clases menos favorecidas. Pero el peso de la tradición de la dependencia, la prédica evangélica y la premisa sobre la confianza que los pobres debían tener en los ricos, parecían tener mayor justificación para la explotación realizada a la población por parte de los empresarios.

Garantizar dicho mecanismo de explotación, exigió el control a través de los tiempos, de los individuos que laboran en la organización, con el ánimo de poder lograr los resultados esperados por ésta. En este caso, la teoría administrativa ha ofrecido diferentes alternativas que conducen a alcanzar dicha premisa a los dirigentes de la organización, así los marcos teóricos que las fundamentan no lo dejen claro y, por el contrario, ofrezcan visiones que buscan favorecer a la clase obrera, o como lo plantea Omar Aktouf sobre el ofrecimiento del espíritu administrativo, “...de posturas y prejuicios previamente destinados a complacer a quienes detentaban el poder, más que a resolver los problemas que el empleado vivía en el trabajo." (Aktouf, 1997, p. 237)

Se puede observar entonces, como las categorías de la biología y de las ciencias sociales, han sido utilizadas para influenciar los modos de pensar y de actuar del hombre en las organizaciones, alimentando el ejercicio de la administración tradicional, en la búsqueda de la maximización del capital a costa de los empleados que deben ser controlados por la alta gerencia con el propósito de lograr tal fin, de la sociedad y de la naturaleza, con el agravante que, desde la óptica de las ciencias sociales, se busca dar explicación de ciertos fenómenos dentro de la organización, como si ésta se tratara de un sistema cerrado donde se puede definir claramente el comportamiento y lo que motiva a los empleados.

Se aspira a dejar marcadas en el argumento líneas que puedan facilitar el inicio de un encuentro de alternativas desde la dirección organizacional, que permitan iniciar cambios fundamentales en la nueva visión que de la acumulación de capital se pueda plantear, con el fin de minimizar los riesgos negativos que se pueden presentar si no se introducen cambios radicales.

\section{Crisis de la administración tradicional}

El ejercicio administrativo de las organizaciones ha exigido siempre resultados cuya valoración, regularmente, ha sido vista desde diferentes ópticas. La información que cada uno de los actores procesa para emitir sus juicios respectivos, varía de un actor a otro. Las opiniones ofrecen infinidad de posiciones con las que la sociedad se enfrenta, intentando encontrar en el ejercicio de la administración y en sus resultados, explicación a la situación actual por la que élla atraviesa.

El ejercicio de la dirección tradicional es valorado bajo el indicador de lo económico, pues es allí, donde se reflejan los resultados obtenidos por las diferentes organizaciones. ¿Pero, en realidad, qué es lo económico y cómo ha sido interpretado por la administración tradicional? El término económico proviene etimológicamente de los vocablos griegos oïkos y nomia, que significan, en resumen, la norma de conducta del bienestar de la comunidad o casa, en un sentido muy amplio (Aktouf, 2001, p.67).

Esta norma de conducta del bienestar de la comunidad encuentra semejanza con la definición del hombre expresada por Aristóteles, cuando menciona que éste es hecho para vivir en conjunto en estado de comunidad. Este estado en comunidad ha llevado al hombre a recorrer diferentes caminos en su historia, uno de ellos ha sido el relacionado con la aparición de la moneda, como medio de facilitación de los intercambios, lo cual ha sido considerado como una de las etapas del progreso humano. 
Sin embargo, la posibilidad de acumulación de la moneda por la moneda, permitió a Aristóteles reconocer dos peligros de importante trascendencia en el mundo de hoy, relacionados con la pérdida de la preocupación por la virtud física, natural de los objetos y el deseo sin límites de la acumulación de la moneda como finalidad primera de las actividades del hombre, en el lugar del bienestar de la comunidad (Aktouf, 2001, p.68).

Según lo anterior, la ausencia en el hombre de la búsqueda del bienestar de la comunidad por su interés en la acumulación de la moneda, lo obliga a asumir comportamientos individualistas que necesariamente atentan contra la supervivencia de la comunidad misma. Lo que es explicado por Aristóteles con la introducción del término crematística, proveniente de dos términos griegos, krema: dinero, moneda y atos: demanda, acumulación, búsqueda, permitiendo distinguir y oponer lo económico de lo crematístico.

En esta misma vía el profesor Edward J. Nell (1992) plantea; si se produce una cosa para producir otra y así sucesivamente, se constituye un proceso infinito que nunca se detendría, significando una renuncia por parte del ser humano a la felicidad, pues ésta nunca se lograría, dado que si el hombre se introduce en ese proceso infinito nunca la alcanzaría y, por el contrario, tenderá a su autodestrucción: "no se puede hacer nada infinito en lo finito".

Con lo relatado hasta aquí, y lo que la sociedad actual esta viviendo, el lector interesado puede concluir que lo económico es tratado en nuestros días como algo crematístico, es decir, dos términos que se oponen, el hombre de negocios de hoy, los ve como sinónimos.

Pero esta situación no es gratuita, pues si estrictamente el significado de lo económico obliga a preocuparse por el bienestar de la comunidad, la pretensión de la economía de considerarse ciencia, la ha llevado a la eliminación de toda consideración ética, reduciendo su función principal a la de constatar y medir, con el fin de rendir cuentas de lo que sucede en la realidad.

Los llamados economistas actuales se preocupan por rendir cuentas del funcionamiento de la economía que desean y organizan aquello cuya visión crematística, los ha llevado a convertirse en círculos dominantes (Aktouf, 2001, p.76-77).
Así, la ciencia económica actual haciendo una mala interpretación de lo económico, se ha convertido en una ciencia de consentimiento y legitimación de aquellos que bajo una posición crematística se han convertido en poseedores de cuantiosas fortunas en detrimento de los más pobres. Pobres que hacen parte de una sociedad individualista como consecuencia del deseo de acumular fortuna, donde el único medio de negociación es su fuerza de trabajo.

Se hace fácil distinguir la valoración que del ejercicio administrativo, en el mundo actual, se invoca desde lo económico como un servicio a la clase dominante. En este sentido, la administración es considerada como un medio para la acumulación de riqueza de unos pocos en deterioro de la naturaleza y de la comunidad en general. En palabras del profesor Aktouf, la administración es considerada entonces, el brazo armado de la economía.

Aseveraciones de lo anterior, se pueden observar en los diferentes artículos escritos por infinidad de autores, uno de ellos Clifford Cobb, quien en su escrito "If the GDP is Up. ¿Why is America Down?" de 1995 ("Si la Productividad y el Empleo están en alza, ¿Porqué América va para abajo?") realza el hecho, cómo los economistas utilizan en esta caso para América, mediciones que no contemplan indicadores oferentes de una verdadera realidad y llama la atención sobre la necesidad urgente de diseñar nuevos indicadores de progreso que se encuentren engranados con la economía que realmente existe. Pues, según él, la economía de hoy ha penetrado en lo más profundo la familia, la comunidad y el hábitat natural y, sin embargo, se siguen midiendo de igual manera los indicadores de la salud y el progreso, por ejemplo.

La posición de Cobb es justificada cuando en su artículo alude a Smith quien se preguntaba ¿Hay una diferencia entre las transacciones monetarias meras y una adición genuina al bienestar de una nación? queriendo decir con esto que la economía actual solo se ha preocupado por medir meras transacciones de intercambio, descuidando aquellas relacionadas directamente con el bienestar de la comunidad.

Otros autores preocupados por el reduccionismo de lo económico, pensado como científico, han expresado sobre los diferentes modelos matemáticos que han sido promovidos, para este caso particular como el de la econometría, que 
sus cálculos y modelos, no son más que ecuaciones sofisticadas cuyo nivel analítico real no sobrepasa el de simples reglas de tres, como ha sido escrito por Samir Amin en su libro titulado "El Imperio de Caos".

Otro ejemplo que permite justificar lo que se ha venido planteando, es el observado en el artículo publicado por Marc-André Gagnon en Julio de 2005 en el observatorio de las Américas titulado "Compétitivité et croissance économique aux EtatsUnis" ("Competitividad y Crecimiento Económico en Estados Unidos"). Donde menciona como la reestructuración llamada neoliberal de los años ochenta, consiguió dejar de un lado el modelo del Estado benefactor para sustituirlo por el modelo de un Estado competitivo.

Si el concepto de bien común pasaba antes por la defensa de los derechos económicos y sociales de la población (planteado de alguna manera por la definición del término económico y la definición que del hombre hace Aristóteles), pasa ahora por la promoción de las empresas e inversores para garantizar el crecimiento económico.

En efecto, con la crisis de la hacienda pública que forzó los recortes en los costos de los programas sociales, se afirmó que sólamente el crecimiento económico podría garantizar la creación de la riqueza necesaria para cubrir las necesidades de la población, de ahí, el imperativo nacional de la competitividad económica con el fin de atraer las inversiones y maximizar la producción.

Gagnon se dedica en su escrito a demostrar cómo en el caso de Estados Unidos, este crecimiento económico como consecuencia de la maximización de las inversiones y de la producción (lo que miden los indicadores actuales de la economía como lo plantea (obb) no certifica el cubrimiento de las carencias de la comunidad, y por el contrario, se acrecientan las desigualdades entre los más ricos y los más pobres.

Como se observa, la administración hoy, es utilizada como un medio de acumulación de riqueza justificada por las clases dominantes que han hecho del ejercicio administrativo en este sentido, una propuesta universal que el Management ${ }^{2}$ debe seguir sin reparo alguno. Esto explica en alguna medida la preponderancia del denominado Management
Americano (clase dominante) frente a otras formas del ejercicio administrativo, que si bien existen en otros países (Alemania, Noruega, Japón) no se les atribuye un carácter de universal, y por el contrario, se les tilda de particulares con la imposibilidad de ser trasladadas a otros escenarios del mundo.

La historia de esta tendencia de la dirección actual, se ha fundamentado bajo la premisa de la acumulación de la riqueza que los empresarios y líderes industriales buscan, afirmando que sus utilidades deben ser rápidas, máximas y siempre en un alza exponencial (Aktouf, 2001, p.164). Esta forma de ver la gestión administrativa, además de alimentarse de lo ya relatado (la visión de Aristóteles sobre las consecuencias del uso de la moneda como medio de intercambio) se alimentó también con la aparición de las propuestas hechas por Taylor y Fayol que sólo buscaban aumentar la producción en tiempos más cortos con el fin de hacerla más rentable.

Las propuestas de estos dos autores surgen como consecuencia de las limitaciones que se le empezaron a imponer a los empresarios por medio de leyes frente a sus obreros, reflejadas en salarios mínimos, condiciones de higiene y de seguridad, vacaciones pagadas, asistencia en caso de enfermedad, horarios estrictos y algunas otras como resultado de la necesidad de contar con votos de carácter electoral, colocando límites a las actuaciones de los empresarios para con sus obreros, las cuales se hicieron más restringidas provocando una disminución en la tasa de utilidad que hasta el momento venían generando.

La plusvalía absoluta que imponían los empresarios, empezó a verse afectada por dicha legislación, haciendo necesaria la búsqueda de nuevas formas de obtener mayor utilidad con la nuevas reglas de juego, originándose lo conocido como la plusvalía relativa, incentivando la aparición de las propuestas que del Management hicieron los autores antes mencionados.

\section{En este sentido Aktouf menciona:}

Era necesario entonces encontrar una forma de plusvalía que permitiera esquivar estas nuevas limitaciones a la plusvalía absoluta. $Y$ este fue el primer resultado ofrecido por la muy fresca "ciencia" del Management:

\footnotetext{
2. Más que pretender una traducción literal del término, éste tiene que ver con el ejercicio administrativo, contemplado como un cúmulo de acciones que se desarrollan por diferentes seres humanos al interior de una organización, con el fin de alcanzar los objetivos trazados por ésta; haciendo necesario que dichas acciones sean manejadas y dirigidas, elementos contemplados en la definición del término management en la lengua francesa, expresada en el libro "La Administración entre Tradición y Renovación” del profesor Omar Aktouf.
} 
la introducción entonces, de la plusvalía relativa, obtenida por la transferencia de la organización del trabajo y del control desde los obreros y empleados de base, hacia los dirigentes y patronos (Aktouf, 2001, p. 166).

A dichas propuestas se les consideró instrumentos capaces de servir de medio para la obtención de la plusvalía relativa. A estas proposiciones se les unió lo que se conoció como plusvalía por la manipulación de las percepciones, que no era otra cosa que el tratar de cambiar la identidad de los obreros y ejecutivos por la "introyección" del ideal organizacional, de manera que asumieran los valores que mediante la cultura empresarial, la organización deseara instalar. Lo que permitiría afirmar, como efectivamente lo hace Aktouf, el regreso mediante estas formas de hipocresía y cinismo, en vía de tal manipulación, a lo mencionado ya como plusvalía absoluta ${ }^{3}$.

Pero esta forma de ver el ejercicio administrativo y la interpretación que de él hace la economía actual, amerita cambios necesarios, si no se quiere tropezar con escenarios negativos en un futuro, pues este individualismo conducente a la maximización ilimitada del capital por unas clases dominantes, no puede ser la visión de un mundo que es limitado, lo que conlleva a unos daños irreparables del hombre y de la naturaleza con la cual interactúa.

Sin querer tomar partido alguno John Kenneth Galbraith plantea "como ha ido transformándose el mundo económico, debe ir también cambiando necesariamente la economía en tanto que es materia de estudio".

Vista la administración actual de los sectores dominantes como un medio para maximizar la utilidad de las organizaciones, y en una búsqueda de nuevas alternativas que eviten las consecuencias enunciadas con anterioridad si se continua de esta manera, desde el análisis económico, es pertinente mencionar lo dicho por Galbraith como una manera de preguntarse de nuevo y encontrar en los tiempos actuales, respuestas más acordes que recojan lo que en un momento determinado lo económico ya ha contemplado pero de lo cual hoy ya muy pocos se acuerdan:

En todo análisis económico y en toda enseñanza de la disciplina es crucial preguntarse qué es lo que determina los precios de los bienes y servicios. Y cómo se distribuyen los beneficios de esta actividad económica ${ }^{4}$. $Y$ qué es lo que determina la participación de los salarios, los intereses, los beneficios, y así mismo, aunque de manera menos preci$\mathrm{sa}$, la renta de la tierra y de otros medios fijos e inmutables utilizados en la producción. A lo largo de la vida moderna de la economía, estos dos temas, la teoría del valor y la teoría de la distribución, han polarizado el máximo interés (Galbraith, 1992, p. 16).

Regresar a estos cuestionamientos se puede considerar un buen principio en la búsqueda de alternativas a la situación actual, pues no se ha mencionado hasta el momento, un elemento que para Aristóteles, era considerado de suma importancia como es el de la ética, pues su visión de la comunidad es aquella en la que el hombre busca el bienestar de si mismo y de sus semejantes y la búsqueda constante de los medios para alcanzar dicho bienestar en armonía con la naturaleza.

La ética está muy relacionada a los temas económicos, pues el alcance del bienestar individual y de los otros está atravesado por este elemento que la disciplina económica actual ha tratado, sin embargo, como juicios éticos que muestran una fuerte tendencia a adecuarse a lo que a los ciudadanos influyentes les resulta agradable creer, reflejando de ese modo lo que en otra obra Galbraith denominó la "Virtud Social Conveniente" (Galbraith, 1992, p.28) alejándose de esta manera del concepto que de ética tenía Aristóteles.

No se debe olvidar además, la adhesión que la administración tradicional ha mostrado por el derecho romano, quien otorgó a la propiedad privada su identidad formal y a su poseedor el dominio de los derechos que hoy se dan por supuestos y que son sumamente amplios, pues abarcan no sólo el uso y disfrute, sino también el mal uso y el abuso. Lo que a oídos del Management occidental puede sonar supremamente armonioso.

Aristóteles visionaba que la búsqueda del bienestar de si mismo y de sus semejantes y de los medios para alcanzar dicho bienestar en armonía con la naturaleza sería afectado con la aparición de la moneda como modo de inter-

3. El lector interesado en esta parte del escrito, podrá profundizar sobre lo mencionado, en el capitulo IV del libro del profesor Omar Aktouf "La Estrategia del Avestruz Racional”.

4. El subrayado es mio. 
cambio, lo que lo llevaría a otro cuestionamiento del cual la economía actual sigue buscando una respuesta. ¿Por qué algunas de las cosas más útiles son las que tienen los precios más bajos en el mercado, mientras que algunas de las menos útiles se cotizan a precios muy elevados? (Galbraith, 1992, p.23).

De lo anterior se puede deducir la importancia que empezó a jugar el valor de intercambio sobre el valor de uso, esto como consecuencia de lo ya expuesto, relacionado con una posición crematística asumida como el significado de lo económico. Permitiéndole afirmar a Aristóteles que "Hay hombres que convierten cualquier cualidad o cualquier arte en un medio de hacer dinero; lo toman por un fin en sí, y creen que todo debe contribuir a alcanzarlo" (Galbraith, 1992, p. 25).

Se debe considerar, entonces, que esta transformación del concepto de lo económico, hoy no se relaciona de manera alguna con su verdadera definición etimológica y, por el contrario, desde la revolución industrial, se contribuyó a la constitución de una figura dominante, la cual ya no recaía sobre aquella vocación de la compra y venta de mercancías, sino que ahora era orientada hacia la producción de las mismas.

Lo cual permitió incomparables posturas por diferentes personajes en variados momentos, entre los cuales se pueden citar a Adam Smith, quien se convirtió en el orientador de directrices en la revolución industrial y Karl Marx, cuya crítica al poder otorgado a los dueños y a la pobreza de los trabajadores como consecuencia del uso de dicho poder, fue su principal preocupación.

Las propuestas de Smith ${ }^{5}$, entendidas por la administración tradicional, sirvieron para fundamentar el deseo por parte de los seres humanos de su dedicación a enriquecerse, situación que siempre había generado desconfianza en tiempos de la Edad Media, incluso en los pasajes bíblicos, pero que a partir de sus propuestas en su tiempo y en nuestros días, han servido para cultivar el propio interés en los seres humanos, por el deseo de maximizar su capital, originando el principio de competencia como una de las condiciones necesarias en un mundo capitalista para el mejor funcionamiento de la economía (Galbraith, 1992, p.85).
A partir de allí, empiezan a aparecer en el escenario económico, diferentes autores que compartían las posiciones de Smith desde la revolución industrial tales como Ricardo y Malthus entre otros, pero a su vez surgen "contradictores", con algún nivel de matiz a dichos enfoques como Friedrich List, Léonard de Sismondi, Joseph Proudhon y Carey, lo que ha permitido abrir hasta nuestros días, un debate económico que si bien, aún no se resuelve, el Management occidental parece haberlo definido a favor de todo aquello que permita la maximización del capital. Más cuando dicho debate, por Occidente, es resuelto bajo la argumentación de que todo depende de la ley de la oferta y la demanda que se presenta en el mercado y que cada uno aprovecha de la manera que más le convenga.

Pero si bien, el lector, frente a la afirmación anterior, puede argumentar que la economía interpretada de esta manera a la que se ha denominado clásica, quien no puede desconocer los resultados que estamos viendo en el mundo actual con la aplicación de sus principios, se ha ocupado de ellos para darles explicación, hace pertinente mencionar cómo dichos resultados han sido sustentados por élla.

Ante la pobreza a la cual se ven sometidos los trabajadores desde la revolución industrial hasta nuestro tiempo, como consecuencia del modelo pregonado y que ha sido asumido por Occidente, ha habido varias respuestas por parte de la economía clásica entre las cuales podemos citar, la mencionada por John Stuart Mill, quien atribuía la pobreza del trabajador en palabras de Galbraith

... a una inmutable ley de rendimientos decrecientes para la mano de obra, a medida que iban incorporándose más operarios al aparato productivo, y por otra, al desenfrenado impulso reproductivo de las masas. En esta misma vena, predicaba lo siguiente. "Poca mejoría puede esperarse en la moralidad mientras no se detenga, del incremento de las familias numerosas. El mismo concepto que se tiene de la embriaguez o de otros excesos físicos" (Galbraith, 1992, p. 131)

Otra de las respuestas venidas a tal situación, fue la planteada por el utilitarismo en cabeza de Jeremías Bentham, que Galbraith menciona en su obra como: 
Aquello que fomentaba la producción era útil o beneficioso, independientemente de que redundara o no en sufrimientos incidentales para las minorías; la regla básica, que se reiteraría interminablemente, era la provisión de "la máxima felicidad para el máximo número". De modo que la infelicidad de las minorías, por aguda que fuera, debía, en consecuencia, ser aceptada... [ ]...el principal objetivo de la humanidad era la búsqueda de la felicidad por parte del individuo y de los bienes que conducían a ese fin, y en segundo lugar, que dicha búsqueda tenía tanto mayor éxito cuanto menos fuese estorbada por orientaciones, intervenciones, restricciones o regulaciones, ya fueran del gobierno o de otros agentes (Galbraith, 1992, p. 132).

A esta altura se quiere dejar al lector reflexionar por el grado de satisfacción que puede considerar le suministran las defensas que la economía clásica da a los resultados que se vienen presentando con motivo del deseo de la maximización del capital por los individuos en la administración tradicional.

Hasta aquí, hay una idea de las vastas fuerzas que motivan la vida y el esfuerzo económico de hoy, es decir, la naturaleza del sistema económico; el rol que empezaron a jugar en el ejercicio administrativo y en la economía temas como los salarios, las rentas, los beneficios y su distribución y la propuesta de los diferentes Estados dominantes con el ánimo de garantizar un progreso económico y de prosperidad (ya ampliamente descrito en el artículo de Gagnon).

La intención es que el lector identifique ciertos elementos de la concepción económica y de las apreciaciones de Aristóteles que pueden ayudar a la interpretación de la situación actual que ha conducido al hombre a profundizar su deseo de individualismo y sus ansias de acumulación de capital, sin medir las consecuencias a futuro de dicho comportamiento, consecuencias que hoy de alguna manera ya se empiezan a percibir.

Como lo menciona Joseph E. Stiglitz en su libro "El Malestar en la Globalización" cuando alude a la labor que realiza el Fondo Monetario Internacional FMI:

... son pocos los que defienden la hipocresía de pretender ayudar a los países subdesarrollados obligándolos a abrir sus mercados a los bienes de los países industrializados más adelantados y al mismo tiempo protegiendo los mercados de éstos: esto hace a los ricos cada vez más ricos y a los pobres cada vez más pobres... y cada vez más enfadados (Stiglitz, 2004, p. 24).

El surgimiento del sinsabor que genera la cita anterior, frente al incumplimiento de la misión que debe regir a la institución a que se hace mención, es evidente. Pues, si su función es aportar dinero a los países que atraviesan coyunturas desfavorables, como consecuencia, en la mayoría de los casos, del mal funcionamiento de los mercados para facilitarles acercarse al pleno empleo, no se entiende cómo hoy este organismo, rinde especial supremacía a la defensa de dichos mercados.

Más cuando muchos de los países que han entrado en crisis, lo han sido como resultado de las recomendaciones brindadas por el Fondo Monetario Internacional relacionadas con las liberaciones prematuras de los mercados de capitales, lo que ha contribuido a la inestabilidad global (Stiglitz, 2004, p.59), pues dicha liberación no vino acompañada de crecimiento como se pregonaba, sino, por el contrario, fue seguida por una profunda miseria.

Lo anterior permite observar cómo las decisiones que se toman en este tipo de organismos internacionales, sólo buscan favorecer los intereses comerciales y financieros de los países denominados industrializados o desarrollados, guiadas únicamente, por ese ya descrito, deseo de maximizar su capital, incluso, olvidándose de toda suerte relacionada con el medio ambiente, la democracia, los derechos humanos y la justicia social (Stiglitz, 2004, p.69), que actualmente se ven tan profundamente afectados en Occidente a razón de la forma como actualmente se piensa la economía y se practica el Management de la clase dominante.

En este sentido, es imposible imaginar, como lo menciona Aktouf, una existencia de los seres humanos en la tierra, que no esté destinada al incansable acaparamiento por el hombre de todo lo que la tierra puede dar, lo que pregona como único ideal, transformar este acaparamiento en riquezas como fin último.

Si se acepta lo anterior, es indiscutible aceptar también, el hecho que el hombre ha 
venido evolucionando hacia la dominación de un materialismo infinito y suicida que desconoce todo orden ético, colectivo y espiritual, pues su postura de acumulación indefinida en un universo que es finito, lo conducirá irremediablemente por el camino de su propia destrucción.

El ejercicio administrativo cuya función última se ha convertido en garantizar el máximo acaparamiento posible de riqueza para unos pocos, bajo una posición crematística, explicada ya con amplitud, ha buscado que sus premisas se conserven en las escuelas de negocios en la actualidad.

La situación actual, aunque tiene un componente histórico que juega roles fundamentales a la hora de pretender encontrar explicación, no debe desviar la atención del papel que en la actualidad cumplen las escuelas de negocios en el mundo. Si bien, el hombre en comunidad asumió comportamientos que han favorecido a unos pocos y perjudicado a muchísimos, la enseñanza de la administración en la actualidad antes que corregir el camino pareciera haberlo alimentado.

Pues se habla del ejercicio administrativo como la búsqueda de "recetas" que permitan el aumento de aquella plusvalía relativa y, ahora nuevamente absoluta, de las cuales ya se ha hablado con anterioridad, que los nuevos directivos deben implementar si quieren ver crecer sus utilidades.

Se puede observar, entonces, como las escuelas de gestión se han convertido en claustros donde los estudiantes esperan encontrar, mediante modelos estadísticos y cálculos sofisticados, los resultados que les permitan garantizar esa maximización de capital, olvidando por completo que en la gestión administrativa la experiencia práctica, el buen sentido, la intuición, la preocupación por lo concreto, la calidad de la relación con el otro, son más determinantes que los modelos actualmente pregonados por dichas escuelas (Aktouf, 2001, p.184).

Se observa como esa "matematización" del ejercicio administrativo, se ha convertido en obligatoria para todos aquellos que en la organización quieren ascender y, además, debe ser convalidada por una escuela de negocios, cuando lo que en realidad sucede con este proceso en el campo de la administración, como lo dice Aktouf es que se está "reemplazando lo real, por el discurso abstracto sobre lo real", originado un administrador supremamente teórico apegado a los cálculos y modelos pero alejado de lo concreto, lo cotidiano y supremamente débil en sus relaciones con sus empleados.

La base conceptual sobre la cual descansa la crematística (acumulación de riqueza), la cual rige la enseñanza del ejercicio administrativo en la actualidad, está dada según Aktouf, por tres confusiones que actualmente son sostenidas y hasta reforzadas: la confusión entre individualismo y libertades individuales, la confusión entre producción-redistribución de las riquezas y crecimiento e infinito-acaparamiento de esas mismas riquezas y la confusión entre relaciones de individuos empresarios "libres de dirigir sus empresas como bien les parezca" y "democracia” (Aktouf, 2001,p.193).

El ejercicio administrativo actual ha fundamentado su teoría y su enseñanza, bajo varios referentes: el de una visión racionalista o instrumental y una positivista, además de un complemento con el funcionalismo utilitarista que se ha constituido en la base epistemológica del pensamiento y el saber de la administración tradicional.

Otro de estos referentes ha sido la visón reduccionista de los trabajos de Taylor y Fayol que fueron interpretados como la ciencia de la organización del trabajo de manera tal que se logra hacer más trabajo en menos tiempo y tal vez el último referente, el relacionado con la creación de la teoría del valor del mercado como resultado del libre juego de la oferta y la demanda que desplazó el valor de las mercancías como consecuencia del trabajo.

Pero toda esta fundamentación teórica del ejercicio administrativo se ha llevado a la mayoría de las escuelas de negocio para ser impartida a través de los llamados métodos de caso, procedimiento sobre el cual, ya se han pronunciado varios autores entre los que se pueden contar Mintzberg, Argyris y el mismo Aktouf, llegando a la conclusión que dicha metodología se fundamenta principalmente en una función heurística limitada al discurso y a la ideología de los dirigentes en los medios de negocios, a una función didáctica dedicada, ante todo, a condicionar, a actuar (decidir) encontrando únicamente en la finalidad de rentabilidad financiera las justificaciones requeridas y en una función pedagógica dispuesta para desarrollar una especie de reflejo argumentado para las escogencias rápidas entre 
decálogos de decisiones de orientación sistemáticamente rentabilísticas. (Aktouf, 2001, p.198).

En este sentido el método de casos:

... posee la virtud particular de ayudar a justificar lo injustificable, en nombre de una moral que se puede, como decía Pascal, "adaptar según las categorías sociales" y, desde luego, acomodar de manera que sea posible 'transigir' con su conciencia. Este acomodamiento y compromiso con la conciencia, ¿no es, por casualidad, una buena manera para resolver, in fine, cualquier escrúpulo económico cuando uno se entrega cada vez más salvajemente, a la crematística? (Aktouf, 2001, p. 204).

Este método pedagógico de la enseñanza del ejercicio administrativo fundamentado en las premisas ya descritas aquí, ha permitido, como lo menciona Henry Mintzberg en su libro "Directivos no MBAs" del año 2004 que "La actual escuela de negocios corriente gira en torno a la especialización, no a la integración; se ocupa de las diversas funciones, no de la práctica de la dirección. Hay asignaturas sobre dirección, pero no son nunca de las más destacadas, se han producido esfuerzos continuados para aumentar su número, pero dicho esfuerzo no ha tenido mucho éxito."

Hace un llamado Mintzberg a fortalecer el escenario de la dirección, como un elemento clave a tener en cuenta en las diferentes escuelas de negocios que debe ser fortalecido, tal vez identificando que la especialización ofreciendo "recetas" no garantiza en manera alguna, los cambios que deben presentarse en la pedagogía y en la práctica de la administración. Pues enseñar la administración únicamente desde la óptica del análisis desprovisto de síntesis, reduce la dirección gerencial a sólo su esqueleto.

Es claro, entonces, que el método de casos como mecanismo para la enseñanza de la administración ha reducido dicho ejercicio a sólo un proceso de toma de decisiones de tipo financiero (crematístico), que como lo plantea Livingston, citado por Mintzberg, presta poca atención al desarrollo de las habilidades necesarias para descubrir los problemas que deben solucionarse, para planificar la consecución de los resultados deseados o para llevar a cabo los planes una vez se hayan establecido.
Distorsionando el crecimiento directivo, ya que desarrolla la habilidad analítica del directivo pero deja sin desarrollar su habilidad para entrar en acción y hacer las cosas (Mintzberg, 2004, p.52). Pues, mientras los directivos en el mundo real trabajan en un caos diario y en un "desorden controlado", los alumnos formados bajo el método de casos se limitan a escribir cifras en formularios estándar alejados de toda realidad. Para Mintzberg, cuando el método de casos se utiliza en lugar de la experiencia, prescindiendo de la historia y obligando a la gente a tomar postura en problemas que apenas conocen, se convierte en una amenaza.

Para concluir esta primera parte del documento destinada a enunciar la crisis que atraviesa la administración de tipo occidental o tradicional, con su posición crematística de lo que debe ser la gestión administrativa, que ha dado origen a una metodología de enseñanza en las escuelas de negocio que le favorece, enunciamos las palabras del profesor Derek Bok de la Harvard University citado por Mintzberg en relación con dicha metodología:

A pesar de que el caso es un dispositivo excelente para enseñar a los alumnos a aplicar la teoría y la técnica, no proporciona una forma ideal de comunicar conceptos y métodos analíticos de entrada. De hecho al concentrarse en la discusión de situaciones detalladas, el método del caso limita el tiempo disponible para que los alumnos puedan dominar técnicas analíticas y material conceptual [...]. Además, el enorme esfuerzo exigido por el sistema de casos puede dejar poco tiempo para que el profesorado anticipe problemas de mayor alcance, o se comprometa en un trabajo intensivo para desarrollar mejores generalizaciones, teorías y métodos (Mintzberg, 2004, p. 78).

\section{Consecuencias actuales de los fundamentos de la dirección dominante}

Analizar las consecuencias actuales de los fundamentos de la dirección dominante, lleva a observar como las dos grandes revoluciones de la economía en la época moderna de Occidente denominadas: la revolución industrial y la postindustrial, no cumplieron con sus promesas de lograr un mundo mejor y mucho más democrá- 
tico, por el contrario, lo que se percibe es una distancia social cada vez más grande.

En este sentido, Aktouf menciona que en pleno siglo XXI, alrededor de tres billones de personas en el mundo viven con menos de dos dólares diarios, significando que ninguna de las revoluciones citadas, ha contribuido a lograr una justicia social y mucho menos a incrementar la igualdad mundial (Aktouf, 2001, p.23).

Lo anterior debido a lo que John Hobson denominó "el exceso de ahorro" o lo que en la actualidad pudiese llamarse "concentración de las riquezas en unos pocos". Es claro que bajo la situación anterior, las personas que concentran la riqueza poseen una capacidad ínfima de consumo, frente a la que tendrían las diferentes personas, si dicha riqueza estuviese distribuida entre un número mayor de gentes.

Sin embargo, los neoliberales de acuerdo a lo anterior, asumen posiciones de defensa argumentando que existe una incompatibilidad "original" entre el mercado y la justicia social y que, seguramente, el comportamiento racional induce a escoger al mercado por encima de la justicia social, lo que no significa más que, suministrar a los grupos dominantes concentradores de riqueza la teoría del funcionamiento de la economía que ellos desean escuchar, como lo ha planteado Robert Haibroner citado por Aktouf.

Pero el lector puede pensar como alternativa ante tal situación que la revolución tecnológica a contribuido alcanzar un mundo mejor y justo para todos como frecuentemente se pregona, lo cual no deja de ser más que una utopía, pues en realidad, lo que ha originado es más polución, desempleados y excluidos, con una única finalidad: hacer crecer los beneficios para los poseedores del capital. Si no, basta traer a colación el significado que de tecnología tienen los dueños del capital "hacer más con menos empleados", lo que no es otra cosa que querer desaparecer el salario.

Los que así piensan han olvidado dos aspectos de vital importancia, uno expuesto por Herbert Simon, quien afirma que las máquinas, los robots y los computadores personales, aunque son productores incansables, éstos no pueden ni consumir ni ahorrar, y el otro mencionado por Carlos Marx, quien dice: a toda organización sistemática de la producción en masa, ha de corresponderle la organización de un consumo en masa (situación que difícilmente se presenta cuando la producción en masa es hecha por máquinas).

La economía que defiende el libre mercado como uno de sus elementos esenciales, ha guardado absoluto silencio ante diferentes situaciones contemporáneas que han venido sucediendo y se han convertido en campanazos de alerta, como las suministradas por Aktouf, cuando afirma que los economistas no han dicho nada frente a ciertos acontecimientos que los obligan a replantear muchas de sus certezas:

Veamos: la atribución del premio Nóbel a un anti-conservador y violento crítico de la ideología de mercado, como el indio Amartya Sen. La denuncia virulenta de los políticos del Fondo Monetario Internacional, FMI, por parte de una revista americana tan prestigiosa como Business Week. Y qué no decir de lo reiterativa que resulta la misma denuncia por parte de personajes tan inesperados, como el ex secretario de Estado de Estados Unidos, Henry Kissinger o el presidente del Banco Mundial (Aktouf, 2001, p. 42).

Dejando, entonces, con mucha debilidad la autoridad que puede darse a los economistas defensores del libre mercado que propugnan por una apertura mundial del mismo. Pues, aunque se esté hoy saturado de técnicas e instrumentos de análisis que suponen ser "racionales" y sofisticados, lo cierto es que la capacidad para comprender y proceder mejor es más pobre frente a la realidad que desafía.

Es decir, la economía liberal se empeña en aceptar lo inaceptable, basada en argumentos que hoy día carecen de una autoridad sólida y rayan con lo absurdo, para justificar lo anterior se da un ejemplo citado por el profesor Aktouf: se ha querido en el análisis del comportamiento del mundo animal justificar las acciones del hombre capitalista actual, al comparar el concepto de acumulación con lo que hacen algunas especies animales como la de los osos, las ardillas o las abejas que, en realidad acumulan pero no más de lo necesario para sobrevivir en el invierno; pero lo que no se ve en dichas especies, y he aquí lo absurdo, es heredar lo acumulado por sus padres o llevar su alimento acumulado a interés compuesto o, peor aún, acumular para su cuenta personal haciendo trabajar para sí a algún inte- 
grante de alguna de las especies mencionadas (Aktouf, 2001, p.47).

No cabe duda que bajo el argumento anterior (amparado en el reino animal), la acumulación de capital se podría ver entonces, como el más preciado de todos los dones para la humanidad, el cual debe ser protegido a toda costa, así se cause desempleo, miseria y exclusión. Es a la luz de esta apreciación que la acumulación de capital generadora de beneficios privados y altos ingresos, no es objeto de ningún control, mientras lo que merece toda atención de ser controlado son los salarios y los precios, es decir, a la empresa o, mejor al jefe, se le a dado la autoridad de tener en sus manos los poderes que han constituido los totalitarismos y los absolutismos, el poder judicial, ejecutivo y legislativo (Aktouf, 2001, p.57).

Es por lo anterior que las escuelas de negocios siguen siendo orientadas al análisis, a la matematización de todas las acciones que en el ejercicio administrativo se deben desarrollar, descuidando por completo la comprensión intelectual de la relación entre las actividades de las empresas y los principales problemas de la existencia humana, impidiendo formar las bases necesarias para un conjunto de relaciones personales. Haciendo que los futuros egresados vean en la creación de valor para los accionistas su elemento más importante de concentración en su ejercicio administrativo, incluso, por encima de las verdaderas necesidades de los clientes y de la calidad de los productos ${ }^{6}$. La formación impartida de esta manera en los programas de MBA (Master in Business Administration) no sólo atrae a cantidades importantes de personas dispuestas a llevarlos a cabo, sino que, además, hace que las empresas estén dispuestas a financiarlos.

Vendiendo a los estudiantes la idea que están siendo formados para dirigir, cuando en la realidad lo que les ofrecen son muy pocas competencias para poder hacerlo, además haciendo de ellos personas arrogantes, poseedoras de todos los poderes que en la empresa se pueden tener, en este sentido Kelly y Kelly escribieron "Es comprensible que los estudiantes de Harvard obtengan un elemento grado de confianza, pues durante dos años en su proceso de formación, han sido inflados y les han dicho que después de sobrevivir en Harvard pueden permitirse considerarse como los mejores talentos jóvenes que el país tiene que ofrecer". Es obvio que esta situación puede favorecer el ingresar a hacer parte de una junta directiva pero los verdaderos problemas vienen después.

Esta idea permanente de las escuelas de negocios de hacerse más científicas tratando de idear "modelos", técnicas y cálculos sofisticados las aleja cada vez más del verdadero ejercicio administrativo, el cual está marcado en gran parte, por la experiencia práctica, el buen sentido, la intuición, el cuidado concreto y la calidad de la relación con los otros. (Aktouf, 2002, p.23). Este modelo premia la competencia desbocada y como lo ha llamado el Grupo de Lisboa, es un "modelo suicida" que ha suprimido toda consideración ética bajo la legitimación del enriquecimiento.

Las escuelas de negocio actuales han fundamentado el ejercicio de la administración, como teoría y como ideología - praxis a partir del concepto importado de Inglaterra de aquella llamada nueva "libertad individual para emprender y enriquecerse", bajo la santa bendición del anglicanismo-calvinismo, del "mercado" y de la "selección natural", aunado además a aquella famosa frase time is money del primer célebre ideólogo del Nuevo Mundo, Benjamín Franklin, integrando a sus procesos de formación la corriente de la escuela de la economía neoclásica nacida a finales del siglo XIX y la visión racionalista-positivista heredada de pensadores como Laplace y Comte (Aktouf, 2002, p.40).

Estos fundamentos han hecho de la formación en administración, la utilización de un método que desarrolla una función heurística que está limitada al discurso y a la ideología de los dirigentes de negocios, cuya función didáctica es ante todo la de condicionar para actuar teniendo en la sola finalidad de la rentabilidad financiera toda la justificación deseada, buscando "moldear las cabezas más que llenarlas".

Como conclusión a esta segunda parte del escrito, no queda sino hacer el reconocimiento que la dirección dominante, como consecuencia de su individualismo, competencia y acumulación de riqueza, hace a la propiedad privada, cuyo

6. Esta afirmación obedece al resultado de una encuesta realizada en al año 2002, publicada por el Aspen Institute donde se reflejan las actitudes que hacia las empresas y la sociedad tuvieron casi 2.000 estudiantes de MBA quienes seguían sus estudios en 13 de las más destacadas escuelas de negocios en Estados Unidos. 
significado etimológico se referencia al verbo privar, proveniente del latín privare, que significa impedir al otro (privarlo) del gozo de alguna cosa por el acaparamiento unilateral de la cosa en cuestión, lo que seguramente permitió afirmar a Albert Jacquard "el humano es la única criatura cuya naturaleza es ser capaz de combatir su propia naturaleza".

\section{Paradigma funcionalista vs. paradigma radical-Humanista}

El paradigma funcionalista aplicado con enorme rigurosidad por la administración tradicional y dominante en Occidente no deja de ofrecer fundamentos (incluso mal interpretados a conveniencia) que lo justifiquen y en este sentido se ha permitido abordar el tema del liderazgo como uno de los elementos esenciales en el ejercicio administrativo. En este sentido, los jefes en la empresa, parecen hoy, estar envestidos de todos los poderes absolutos que han constituido los totalitarismos y los absolutismos, el poder judicial, ejecutivo y legislativo, esto ha hecho que sus subalternos los vean como "dioses sobre la tierra" o "gente que se cree nacida de una criatura extraterrestre", que ha permitido que la llamada gerencia de la excelencia haga una deificación del dirigente que ahora se conoce como el líder y una reificación o despersonalización de los empleados; pues como ya lo mencionaba Hegel, su principal preocupación consistía en la "pérdida del hombre en el mundo de los objetos", que ha dado paso a la enajenación del hombre en el trabajo (Aktouf,1994,p.125-150).

La administración tradicional ha traído conceptos de otras áreas como la biología (la propuesta darwiniana, el comportamiento de algunas especies en el reino animal), la teología (la propuesta calvinista) y las ciencias sociales para encontrar justificación a sus acciones, el caso de la teoría del liderazgo no ha sido la excepción.

El liderazgo nace en Normandía para el siglo $X, y$ uno de sus representantes, el rey Rollon, le imprimió una de sus características principales, todo el que quisiera podría hablar con él o en su defecto con uno de sus representantes, el poder de Rollon fue heredado por su hijo Guillermo que actuaba de la misma forma que su padre cuando conquistó Inglaterra, su forma de ejercer liderazgo no cambió, sólo que en Inglaterra, como en el caso de Normandía, no existía una justifi- cación trascendental para el poder que poseía Guillermo más allá de que su comportamiento era igual que al de cualquier mortal; la verdadera legitimación de dicha figura que ostentaba el poder se dio para el siglo XIV en Inglaterra, con la creación por parte de los jueces del llamado "el segundo cuerpo del rey" que no era más que la mención a que el rey tenía dos cuerpos: uno físico y otro divino, por esto se justificaba que cuando el rey moría, lo que desaparecía era su cuerpo físico y su cuerpo divino era transmitido a sus hijos, lo que ha justificado la herencia del poder en la nobleza.

Qué ha pasado con el mundo empresarial de la dirección dominante, frente a un tema como este?. Es bien sabido que los empresarios o más bien, jefes de empresa, no tienen ninguna justificación trascendental (pues no son nobles) que justifique su ostentación de todos los poderes en la organización, por lo cual la administración dominante creó la conocida teoría del liderazgo haciendo una analogía (como siempre lo ha hecho con la mayoría de sus postulados) con el ya descrito "el segundo cuerpo del rey" de Inglaterra, argumentando que el líder es una persona que posee una serie de características que le son propias y únicas desde el punto de vista de su posesión, lo que le brinda la posibilidad de generar respeto.

El verdadero problema, entonces, no radica en el liderazgo como tal, sino en la forma como ha sido construido por Occidente para justificar su administración dominante en las empresas, pues presenta la figura del líder como algo artificial, cuando en realidad el líder es de ocasiones, de contextos y aparece para ciertos momentos ante algún tipo de situación, el líder no es permanente como lo ha querido hacer ver la administración tradicional, pues, si existe un líder (bajo la figura de Occidente) significa que otros no lo son y al no tener esas características propias del líder, se ocasiona, entonces, en las empresas, la imposibilidad de participación y colaboración de todos, dando al líder de Occidente la omnipotencia absoluta, si él no hace las cosas nadie más puede hacerlas. Esta omnipotencia otorgada al líder, hace que el jefe tolere cada vez menos aquello que en la organización no se identifique con sus visiones y deseos, invitándolo a "eliminar" todo aquello que decepcione o no glorifique a la dirección (incluso a los empleados), o, lo que es lo mismo, no colabore con la generación de acumulación de capital. 
He aquí la necesidad de separar los conceptos de liderar y de dirigir como lo plantea Mintzberg:

Esto lleva a la consecuencia definitiva de separar liderar de dirigir. A los MBA no se les enseña a dirigir y muchos carecen de voluntad para hacerlo. Pero están decididos a liderar. De modo que desarrollan una trayectoria que los lleva por la dirección al liderazgo. El problema, como veremos más adelante, es que muchas de estas personas se convierten en líderes horribles, precisamente porque tienen las manos alejadas del negocio. De hecho el paisaje de la economía actual está plagado de cadáveres de empresas dirigidas por individuos cabezotas que nunca aprendieron los detalles de sus negocios (Mintzberg, 2004, p. 107).

Sin embargo hoy, los líderes de empresa, siguen siendo esos jefes sentados en sus pedestales, alejados de todo y muy bien recompensados, donde todos los demás esperan acongojados su siguiente movimiento. El liderazgo no consiste en tomar decisiones inteligentes ni en hacer grandes negocios, y mucho menos hacerlos para beneficio personal, su verdadera esencia consiste en llenar de energía a los demás para que tomen buenas decisiones y hagan las cosas cada vez mejor.

El liderazgo efectivo inspira, más que dar poder; conecta, más que controlar, demuestra, más que decidir, pero aún así, las escuelas de negocio siguen manteniendo una formación en liderazgo que viola su verdadero espíritu y, por el contrario, ayuda a la creación de una élite aislada y privilegiada, que normalmente se impone sobre la gente sin su consentimiento (Mintzberg, 2004, p.164). Ayudando a hacer de la avaricia una especie de vocación que hace que en las empresas se ignoren las responsabilidades sociales a favor del valor para el accionista y se hace creer a los altos ejecutivos que ellos son los únicos que crean rendimiento económico.

Todo este grado de egoísmo e individualismo fortalecido por la administración tradicional bajo todos los postulados que pregona, han trascendido a la cultura dandole la razón a Marcuse, cuando ve estos elementos progresivos en la cultura de masas, como la perversión que señala el hecho de que la sociedad industrial avanza y se enfrenta a la posibilidad de una materialización de todos los ideales, donde el hombre y la naturaleza son organizados como cosas e instrumentos, haciendo que en el campo de la cultura, el nuevo totalitarismo se manifieste precisamente en un pluralismo armonizador, en el que las obras y verdades más contradictorias coexisten pacíficamente en la indiferencia (Marcuse, 1968, p.89-117), provocando una civilización unidimensional; unidimensionalidad que hace que el funcionalismo que es practicado por la administración tradicional y dominante, cubra con un tabú su propio ser, haciendo que su propuesta de carácter racional siga siendo irracional.

Esta funcionalidad ha llevado a la sociedad a que todo lo que toca se convierta en una fuente potencial de progreso y explotación, de cansancio y satisfacción, de libertad y opresión que alimenta una destrucción realizada por el hombre que es vista como normal tanto en el patrimonio mental como en el material de la gente. En palabras de Marcuse,

Asumiendo que el instinto de destrucción (en último término: el instinto de la muerte) es un amplio componente de la energía que alimenta la conquista técnica del hombre y la naturaleza, parece que la creciente capacidad de la sociedad para manipular el progreso técnico también aumenta su capacidad para manipular y controlar este instinto, por tanto, para satisfacerlo "productivamente". Entonces la cohesión social será fortalecida en sus más profundas raíces instintivas. El riesgo supremo, e incluso el hecho de la guerra, serán afrontados no sólo con una resignada aceptación, sino también con una aprobación instintiva por parte de las víctimas (Marcuse, 1968, p. 119).

Ocasionando lo que el mismo Marcuse ha llamado una falsa conciencia, donde pareciese, se han atrofiado los órganos mentales de los hombres que le posibilitaban comprender las contradicciones y las alternativas y sólo se ha dado paso a una única dimensión permanente de racionalidad que refleja la creencia de que lo real es racional y de que el sistema establecido, a pesar de todo, proporciona los bienes, originando un nuevo conformismo. Por eso, ante la destrucción de los recursos naturales y la proliferación del despilfarro como prueba de opulencia, la comunidad está demasiado satisfecha como para preocuparse. 
Ha sido tal la fuerza de esa unidimensionalidad, que se ha logrado construir un discurso en que los opuestos se reconcilian y tienen una firme base para tal unificación: su provechosa destructividad. La unificación de los opuestos que caracterizan el estilo comercial y político es una de las muchas formas en las que el discurso y la comunicación se inmunizan contra la expresión de protesta y negación (Marcuse, 1968, p. 119-158).

De lo anterior podemos dar un ejemplo que lo resume todo, es la investigación que se pregona realizada recientemente por la Universidad de Erasmus de Rotterdam (Holanda), quien desarrolló un banco de datos sobre la felicidad a nivel internacional, lo asombroso de la falsa conciencia que hemos venido hablando citando a Marcuse, que da origen a una construcción de un discurso donde los opuestos se reconcilian, es ver cómo a partir de la investigación mencionada se han conocido titulares a nivel mundial como "Bangladesh, los más pobres pero los más felices", lo que convierte este tipo de discurso en intimidante y glorificado.

Como se ve, estos términos así utilizados designan esferas o cualidades bastante diferentes (para este caso pobreza y felicidad) que son forzados a una unión que los convierte en una sólida, todo poderosa totalidad. El efecto como lo dice Marcuse, es mágico e hipnótico, es la proyección de imágenes que sugieren una irresistible unidad, una armonía de contradicciones, no es más que el lenguaje funcionalizado, contraído y unificado: es el lenguaje del pensamiento unidimensional, en otras palabras es el ingreso de lo negativo en las determinaciones positivas de la lógica.

Esto es lo que practica la administración tradicional y dominante, unas nuevas definiciones que siendo falsificaciones, son impuestas por los poderes de hecho que sirven para transformar lo falso en verdadero.

Sin embargo, la administración tradicional y dominante no se ha detenido a analizar cómo todo su accionar niega y contradice las leyes de la física con sus debidas consecuencias. Lo anterior tendría que ver con el pensamiento que el hombre ha venido manejando ¿Qué significa la vida? y ¿Cuál es la interpretación que de ello ha hecho?. En este sentido, Erwing Schrodinger plantea "La vida es la capacidad de extraer orden de su entorno" (Aktouf, 2001, p.225) y, aunque efectivamente, el hombre lo hace para poder vivir, lo cierto es que es el único ser que extrae de su medio más orden del que es necesario para mantenerse como una estructura viva.

Pero si bien, lograr el crecimiento y la supervivencia obliga al hombre a extraer de su medio más orden del necesario, la interpretación maximalista impuesta por el paradigma neoclásico, ha interpretado el crecimiento como un máximo indefinido que supone la posibilidad de una acumulación indefinida que es imposible de lograr cuando el orden que extrae del medio no es indefinido.

Los diferentes argumentos enunciados en el documento son más que suficientes para reconocer que se hace necesario recorrer nuevos caminos que ofrezcan un panorama mucho más favorable. Es allí donde el paradigma del radicalhumanismo ofrece alternativas, el enfoque "radical humanista" se desarrolla en oposición a la función utilitarista de la administración tradicional.

La propuesta humanista-radical, considera el discurso de la dirección dominante como una forma ideológica empleada por los dirigentes para asegurar que las acciones de los miembros de la organización se dirijan al logro de los objetivos planteados por ellos. Los dirigentes lo utilizan conscientemente para obtener el respaldo necesario para el logro de sus objetivos.

La perspectiva radical-humanista propone un cambio en el rol primordial de los dirigentes, ella exige un compromiso auténtico y personal por parte de estos que se exprese en comportamientos menos burocráticos y más humanos. Crozier escribe al respecto

El rol del dirigente no es el de dar ordenes imperativas y de imponer reglas de costumbres que lo haga posible, el jefe debe convertirse en un verdadero animador en lugar de dirigir desde su oficina, el debe ser capaz de hacer dar confianza a los subordinados, de ayudarles, de facilitarles sus tareas y de permitirles a través de estas tareas afirmar su personalidad.

Aktouf a partir de la experiencia de una empresa quebequense (el caso Cascades) de pulpa y de papel toma los fundamentos de un nuevo comportamiento de empresa y recomienda, entre otros, un modo relacional oral generalizado, sis- 
tematizado, un estilo de gestión orgánico donde domina el ajuste mutuo, una apertura real en todos los sentidos, una política de transparencia y de difusión de la información, el compartir de los beneficios y de la disponibilidad del material de la empresa, etc., todas estas prácticas deben reposar sobre una voluntad sincera de compartir. Esto se puede resumir en la frase, "actuar y vivir".

El radical humanismo no ve el ejercicio administrativo como una simple herramienta de gestión, sino una nueva perspectiva de análisis y de estudio de las organizaciones. Para esta perspectiva la empresa es el lugar de transformación de la experiencia colectiva en sistema de reglas legitimadas. Sainsaulieu escribe en efecto "que la experiencia del trabajo es creadora de comportamientos. Ella impresiona al sujeto hasta el punto de hacerlo modificar las prioridades y la racionalidad que el tiene de su educación, su moral o su religión. El comportamiento entonces hace parte integral de la empresa y su análisis o su práctica aclara el funcionamiento de los grupos humanos en la organización".

La perspectiva radica-humanista reconoce la importancia entre las interacciones de la empresa y su medio (nacional, regional o profesional), en la creación de un ambiente distinto al tradicional, las tradiciones sociales y religiosas de las sociedades impregnan los comportamientos en la empresa, como los individuos no pueden admitir simultáneamente sistemas de valores contradictorios, las empresas deben asegurarse de la compatibilidad de sus prácticas con los comportamientos nacional o regional.

El radical-humanismo desenmascara el carácter ideológico de las organizaciones de la corriente funcionalista que sirve a los intereses de los dirigentes, propone una nueva perspectiva conceptual, una relación de recambio en relación con las teorías dominantes, que como dice Sainsaulieu "Después de la propensión del control del producto, después de la apropiación del control del proceso, el patrón desea apoderarse hoy en día del sistema de valores del trabajador".

En este sentido se diferenciarían dos formas del ejercicio administrativo; aquella que se caracteriza por la tradición jerárquica piramidal, la separación entre concepción y ejecución, la diferenciación de roles, propia de la administración dominante y la otra, casi a la inversa, caracterizada por la interacción continua entre concepción y ejecución, la intersección generalizada entre escalones y funciones, los lazos sistemáticos y en tiempo real entre terreno, sitio y la alta dirección, la permeabilización constante de las estructuras y de los niveles, haciendo de la primera un ejercicio administrativo que propicia relaciones de tipo contrato y de reportes forzosos, mientras que la segunda es del tipo contrato pero de negociación y consentimiento. (Aktouf, 2001, p.210).

Es por lo anterior que hoy se observan posiciones como la de Michel Albert, Lester Thurow y Alain Minc que ofrecen, cada vez más convencidos, dos formas radicales de capitalismo: aquel calificado de "especulador financiero a corto término", que se lleva a cabo en los Estados Unidos, en el Reino Unido, en Francia o en Suiza; y aquel calificado de "productivo-industrial a largo término" que sería aplicado en Japón, en Asia del sureste, en Alemania, en Austria y en el conjunto de países escandinavos. Los primeros aplicando el ejercicio administrativo de tipo tradicional y dominante y los segundos más inclinados a aplicar una administración enfocada más en la dirección que en el liderazgo, que los ha hecho encontrar otras concepciones y otros factores de éxito: ya no tratando de hacer más, y más rápido al menor costo, sino de hacer mejor, más creativamente, más inteligente y más fiable cada tarea, incluso y sobre todo, en los más bajos niveles de la organización, haciendo que la era de la calidad y de la creatividad extienda sus exigencias y muestre que todos los empleados deben ser parte prensil, activos y pensantes en lo relacionado con su contribución a la organización (Aktouf, 2001, p.279).

Lo que hace de este movimiento hacia el paradigma radical-humanista en las organizaciones no un ideal romántico, ni un acto de filantropía gratuita, ni una utopía, sino una necesidad.

\section{Conclusión}

Los hombres ubicados en la "cúpula" de la organización ven en el discurso de la administración tradicional, elementos que les favorecen en la práctica, pues las acciones de planear, organizar, dirigir y controlar a los hombres, les permiten lograr las metas trazadas por la organización. De otro lado, los hombres ubicados en la "base" de la organización, no encuentran espacio y no son reconocidos en el discurso, como seres humanos que en el ejercicio administrativo pueden tener aportes importantes, a la hora de tomar decisio- 
nes al interior de la organización, cuya función desde la tradición ha sido facultativa de una persona o un grupo minoritario en la empresa.

Pareciese pasa desapercibido en el pensamiento administrativo tradicional, que los integrantes llegados a una organización proceden de un orden social espontáneo y que entran a formar parte de un orden social creado $^{7}$, como lo es la organización que obliga a que los comportamientos de esos integrantes no necesariamente se vean influenciados sólamente por ese orden social creado sino, por el contrario, hay una alta dosis de decisión de comportamiento influenciado por el orden social espontáneo a que pertenece cada integrante que llega a la empresa.

Los comportamientos de cada integrante en la organización se verán mayormente influenciados por las experiencias que cada integrante de la empresa haya vivido en ese entorno social espontáneo que lo invita a procurar que en la organización para cual labora, encuentre la satisfacción de las necesidades que dicho entorno le genera marcadas por una alto dosis de individualismo en la búsqueda de generación de ingresos suficientes ${ }^{8}$.

Las prácticas administrativas actuales en las organizaciones, influenciadas por un discurso administrativo tradicional, no dejan claro que el ser humano encuentre hoy en la organización la satisfacción total de sus necesidades y, por el contrario, vea en la labor en la empresa, como contraprestación, un aporte temporal y parcial que lo ayude a colmar en parte y no de manera satisfactoria algunas de ellas.

Además de tener la sensación que es utilizado por la organización para que esta maximice sus intereses y donde le exigen desarrollar valor agregado en sus oficios, el cual no le es devuelto en modo alguno por la organización. Es indudable que la lealtad de los trabajadores de hoy para con sus organizaciones ha disminuido de manera importante como consecuen- cia de esa misma sensación de baja de lealtad de la organización para con ellos.

Teniendo en cuenta que el hombre juega un papel trascendental, y considerando la organización como un ente social creado donde ingresan los hombres y las mujeres, es de aceptación importante que estos "empleados" desarrollan conocimientos, creencias, costumbres y actitudes que harán que sus comportamientos se vean influenciados por dichos desarrollos al interior de la empresa. Situación que el discurso administrativo tradicional basado en la maximización de las utilidades por parte de la organización no ha abordado de manera rigurosa ${ }^{9}$.

La preocupación por el comportamiento del hombre en la organización, invita en principio, a tener en cuenta la diferencia de actividades que éste puede desarrollar al interior de la misma, relacionadas con la parte operacional o de alta gerencia ${ }^{10}$, a lo cual el discurso administrativo tradicional pretende dar respuesta con un abanico de posibilidades que guían el comportamiento, que bajo su fundamento de la concepción de organización, deben tener los hombres cuyas actividades están relacionadas con la alta gerencia, donde incluso, no se toca al hombre que desarrolla actividades de orden operacional, más que como un objeto de estudio, cuyas conclusiones deben servir a los hombres de la alta dirección organizacional.

No hay duda, el discurso administrativo tradicional, enfrenta hoy, desafíos que implican el desarrollo de una nueva construcción del conocimiento administrativo, pues la ubicación del hombre en la organización, de acuerdo a las actividades que realiza y las experiencias hasta hoy vividas en el campo organizacional, invitan a empezar, por el reconocimiento de lo humano que está presente en el inevitable choque de intereses expresado aquí, lo anterior, seguramente, permitirá reforzar el hecho que mediante un cambio del orden social, se puede garantizar un aumento en los niveles de vida (Heilbroner,1968,p.226). Cambio que, desde el punto de vista de la organización, supone el

8. En la sociedad actual el hombre busca el lucro de su labor y lo desea ver reflejado en ganancias que le permitan sobrevivir.

9. La existencia del estudio en la administración de temas relacionados con la cultura organizacional, desarrollo organizacional, clima organizacional que abarcan temáticas de lo que aquí se plantea, han estado fundamentados en el discurso administrativo tradicional y sus conclusiones van orientadas a cómo las organizaciones pueden aumentar la maximización de sus utilidades bajo la acumulación de capital.

10. Debe entenderse la división de las labores operativas y de gerencia como la posibilidad de encontrar en ellas comportamientos diferentes desde el punto de vista organizacional por las funciones de cada una y por los seres humanos que las desempeñan 
dejar de considerar a los integrantes de la misma como máquinas, y por el contrario, hacer de ellos socios de la alta gerencia, que pueden cooperar en el alcance, con sus propias decisiones, de los objetivos trazados por la empresa. Pero esta cooperación parte del hecho que el trabajador encuentre en su organización la posibilidad de satisfacer sus propias aspiraciones, conduciéndolo a generar procesos de reflexión y creatividad que le permitan tomar decisiones propias y no inducidas.

Surge, entonces, la necesidad de trabajar en la probabilidad que el desarrollo del cooperativismo entre estos dos actores divididos tradicionalmente como consecuencia del ejercicio administrativo actual, amparado en lo tradicional, pueda ofrecer sus frutos en medio del capitalismo.

Es necesario que la mirada actual de lo económico y de la administración, regida por la clase dominante, donde se premia la maximización de las utilidades, vía la maximización del trabajo para obtener resultados en un menor tiempo, con consecuencias negativas para los obreros y las clases menos favorecidas, sufra un salto que es necesario dar, el cual no debe ser concebido en términos de grado sino de naturaleza, pues no se trata de sólo promover el cambio de fórmulas u ofrecer unas "recetas" nuevas sino de analizar de nuevo los fundamentos.

Analizar las bases claves de las relaciones entre el capital, el trabajo y la naturaleza, seguramente conducirá a un cambio radical en la manera de analizar la economía, las empresas, las organizaciones y el ejercicio administrativo. La nueva forma de vivir las relaciones de producción y de trabajo deberá aflorar (Aktouf, 2001, p.173).

El tiempo apremia y no da espera, las consecuencias serán negativas en la medida que sigamos premiando la maximización de las utilidades a cualquier precio, pues debe quedar claro, el problema no son las utilidades en si mismas, el problema central es a costa de qué se logran.

Alternativas que puedan dar inicio a debates que faciliten los cambios necesarios que provoquen armonía entre los actores involucrados en el ejercicio administrativo y que, seguramente, merecen seguir siendo profundizadas, implican que la actividad gerencial contemple una serie de acciones al interior de las organizaciones que motiven una visión diferente de dicha actividad.

En este sentido, se considera que todos los actores de la organización, independientemente del cargo que ocupen, deben, darle sentido al trabajo que realizan, lo cual se debe ver reflejado en la expresión de voluntad y deseo de quien lo hace; un punto de partida para lograr dicho objetivo será reconocer que todos los seres humanos que laboran en la organización son individuos pensantes, donde la comunicación se presenta como uno de los elementos transcendentales que debe ser repensada, pues mientras en la administración llamada tradicional, dicho elemento se ha utilizado como medio de control y dominación, la acción presente indica que debe ser utilizado como un mecanismo de puesta en común entre todos los integrantes de la organización, lo que deberá conducir a la apropiación, por todos los miembros, de las diferentes actividades que realizan donde se refleje el respeto, la autonomía y la autodeterminación de los mismos.

De otra parte, la organización deberá garantizar que todas sus actividades se desarrollan con total transparencia y que están guiadas por premisas que respetan la dignidad humana y la naturaleza con el ánimo de "seducir" a sus integrantes de manera que encuentren ese sentido de lo que hacen y que se convierte en el gran reto de la administración de las organizaciones del siglo XXI.

\section{Referencias}

Aktouf, O. (2002). Administración y Pedagogía. Colombia: Editorial Universidad Eafit.

Aktouf, O. (2001). La Metodología de las Ciencias Sociales y el Enfoque Cualitativo en las Organizaciones. Colombia: Universidad del Valle.

Aktouf, 0. (2001). La Estrategia del Avestruz Racional. 1a. ed. Colombia: Artes Gráficas del Valle Ltda. 379 p.

Aktouf, O. (1997). La Administración entre Tradición y Renovación. $3^{3}$. ed. Colombia: Gaëtan Morin éditeur y Universidad del Valle. 750 p.

Aktouf, O. (1996). Le management de l'excellence : de la déification du dirigeant à la réification de l'employé. T.C. Pauchant, dir. La quête du sens, HEC presses, Éd. D'organisation : 213-236. 
Aktouf, 0. (1991). Adhésion et pouvoir partagé. Gérer et Comprendre : 44-57, Jui.

Aktouf, O., Bédard, R. et A. Chanlat. (1992) Management, éthique catholique et esprit du capitalisme : l'exemple québécois. Revue Sociologie du travail, 92, (1) : 83-99.

Albert, M. (1992). Capitalismo contra Capitalismo. Barcelona: Paidos. 256 p.

Amin, S. (1991). L'empire du Chaos. Paris: L'Harmattan.

Argyris, C. (1993). Education for Leading-Learning. Organizational Dynamics, 21, (3) : 5-17.

Bennis, W.G. \& J. O'Toole. (2005). How Business Schools lost their way. Harvard Business Review.

Calvez, J.Y. (1970). L'économie du XIXe siècle: le travail aliéné y L'aliénationéconomique fondamentale dans le capitalisme. En su : La pensée de Karl Marx. Paris. Éditions du Seuil. Pp. 131-146 y 167-190.

Cobb, C; Halstread, T and Rowe, J. (1995). If the GDP, Why is America Down? Atlantic Monthly: 59-78.

Crozier, M. (1964). The Bureaucratic Phenomenon. Chicago: Tavistock Publications, University of Chicago Press.

Gagnon, M. (2005). Competitivite et croissan économique aux Etats-Unis. Cui Bono"? La Cronique des Amériques, (4).

Galbraith, J. K. (1998) Historia de la Economía. 8‥ ed. Barcelona: Editorial Ariel S.A. 336 p.

Georgescu-Rogen, N. (1995). La Décroissance. Genève : Éditions Sang de la Terre.

Gould, S. J. (1997). Los huesos mondos de la selección natural y Epílogo sobre la cultura humana. En su: La Grandeza de la Vida. Barcelona. Drakontos. Pp. 147-157 y 232-244.

Heilbroner, R. (1968). Las Herejías de John Maynard Keynes y Más allá de la Revolución Económica. En su: Vida y Doctrina de los grandes Economistas. Madrid. Ed. Orbis. Pp. 65-107 y 215-237.
Jacquard, A. (1978). Éloge de la différence. Éditions du Seuil.

Marcuse, H. (1968). L'homme unidimensionnel : essai sur l'idéologie de la société industrielle avancée. Paris : Les Éditions de Minuit. 288 p.

Nell, E. J. (1992). Economics as Worldly Philosophy: Essays in Honor of Robert Heilbroner, edited with Jaspal Chatha and Ron Blackwell. London, UK: Macmillan.

Minc. A. (1989). La Grande Illusion. Paris : Grasset.

Mintzberg, H. (2004). Directivos no MBAs. Barcelona: Deusto. $487 \mathrm{p}$.

Sainsaulieu, R. (1995). Sociologie de l'entreprise : organisation, culture et développement. Paris : Dalloz, 1995.

Stiglitz, J. E. (2004). El Malestar en la Globalización.

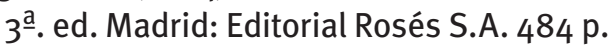

Taylor, F. W. (1997). Fundamentos de la Administración Científica. En su: Principios de la Administración Científica. México. Herrero Hermanos. Pp. 18-40.

Thurow, L. C. (1996). The Future of Capitalism. New York: Penguin Books.

Veenhoven, R. (2008). Investigación sobre la Felicidad. Universidad Erasmus de Rotterdam, Países Bajos. Investigación de Indicadores Sociales. 